Article

\title{
Organic Acid Regulated Self-Assembly and Photophysical Properties of Perylene Bisimide Derivatives
}

\author{
Ying Wang, Xinguo Yang *, Siyu Li, Tao Long and Wei Li(D) \\ College of Materials Science and Engineering, Hunan University, Changsha 410082, China; \\ jhers950420@163.com (Y.W.); lisiyu199512@163.com (S.L.); longtao@hnu.edu.cn (T.L.); \\ liwei5168@hnu.edu.cn (W.L.) \\ * Correspondence: xgyang@hnu.edu.cn
}

Received: 14 March 2020; Accepted: 30 March 2020; Published: 3 April 2020

\begin{abstract}
In this work, perylene bisimide derivatives (PBI-1 and PBI-2) with tertiary amine groups were designed and synthesized. To control the final morphologies and properties of their aggregates, seven kinds of organic acids were used to alter the self-assembly environment. The influence of organic acids on the morphology of the aggregates was investigated. Photophysical properties of the aggregates were markedly affected by the kind and concentration of the organic acid. The thermal and gas sensitivities of the PBI-1 aggregates were studied with the use of UV-visible spectroscopy and digital imaging. The shift of the UV-visible spectra varied with time, temperature, acid type and acid concentration. Furthermore, PBI-1 aggregates showed a red-to-blue color change after addition of seven organic acids, whereas the color of the PBI-2 aggregates remained red. These changes of morphologies, photophysical properties and their thermal and gas sensitivities make these aggregates potentially useful in the fields of optoelectronics or sensors.
\end{abstract}

Keywords: perylene bisimide; self-assembly; organic acid; thermal sensitivity; gas sensitivity

\section{Introduction}

In recent years, many functional nanomaterials have been synthesized through the use of self-assembly. The driving forces for self-assembly include non-covalent interaction forces, such as $\pi-\pi$ interactions, hydrogen bonding, hydrophilic/hydrophobic interactions, van der Waals forces and charge interaction forces [1-4]. $\pi$-Conjugated systems have attracted great attention for applications to self-assembly mainly because of their designable molecular structures and excellent optoelectronic properties. However, the driving forces for self-assembly in $\pi$-conjugated systems involve $\pi-\pi$ interactions, hydrogen bonding, van der Waals forces, and solvophobic interactions, and rarely include Coulomb forces. Coulomb forces interact with $\pi-\pi$ interactions in self-assembly and can change the morphology and properties of aggregates. Specifically, Coulomb forces adjust the magnitude of $\pi-\pi$ interactions and thus change the molecular stacking mode. This is an unusual case and is typically only achieved in fused ring molecules.

Perylene bisimide is an excellent $\pi$-conjugated system that has strong $\pi-\pi$ stacking interactions and can form nanomaterials with various morphologies through 'bottom-to-top' self-assembly, such as rods, wires, belts and tubes [5-8]. These aggregate structures have a rich variety of optoelectronic properties; hence, perylene bisimide derivatives are widely used in solar cells [9-12], field effect transistors [13-16], light-emitting diodes [17-19] and sensors [20-24].

In general, the molecular structure and assembly conditions of perylene imide markedly affect the morphologies and properties of its aggregates. Zang [25] introduced linear dodecyl and branched 
nonyldecyl at the imide position of PBI, which aggregated into nanoribbons and into nanospheres when substituted with linear dodecyl chains and branched nonyldecyl chains, respectively. Yang [26] has reported that amphiphilic PBI molecules form nanotubes in methanol and nanoribbons in methylcyclohexane. Yao [27] synthesized PBI molecules by introducing a pyridine group at the bay position and discovered that adding hydrochloric acid changed the aggregates from nanodisks with weak fluorescence to nanospheres with strong fluorescence. Therefore, PBI aggregates with different morphologies, and optical properties can be obtained by changing the molecular structure, solvent polarity, $\mathrm{pH}$ value, molecular concentration, temperature and other conditions [28-32].

The tertiary amine group is a strong electron donor and can be easily protonated [33]. In our previous research, it was found that morphologies and properties of aggregates can be significantly influenced by hydrochloric acid and the molecular structure of PBI with tertiary amine groups. However, the situation of organic acids has not been involved, and there are few reports on the effect of organic acids on PBI aggregates.

In the present work, we report on the design and synthesis of PBI-1 and PBI-2 substituted with tertiary amine groups, and self-assembled in seven organic acids (namely, p-toluenesulfonic acid, oxalic acid, malonic acid, citric acid, formic acid, glutaric acid and acetic acid) through the use of the rapid solvent diffusion method. Morphologies, photophysical properties, and thermal and gas sensitivities of PBI-1 aggregates were investigated by digital imaging, polarized light microscopy (POM), field emission scanning electron microscope (SEM) imaging, UV-visible (UV-vis) spectroscopy and fluorescence spectroscopy. Changes of the morphologies and photophysical properties of PBI-1 aggregates assembled in organic acids are discussed. These results provide a basis for subsequent design of perylene bisimide nano-optical functional materials and their applications in sensors.

\section{Experimental Section}

\subsection{Materials}

All reagents were purchased from Shanghai Aladdin Bio-Chem Technology Co., Ltd. (Shanghai, China) and used directly without further purification. 1,6,7,12-Tetra(4-tert-butylphenoxy)-perylene3,4,9,10-tetracarboxylic bisanhydride was prepared according to procedures described in the literature [34]; $\mathrm{N}, \mathrm{N}$-dimethylethylenediamine, 3-dimethylaminopropylamine and imidazole were of analytical reagent grade and used as received. Other reagents were analytically pure unless stated.

\subsection{Synthesis and Characterization}

\subsubsection{Synthesis of PBI-R}

PBI-R was synthesized according to previously published procedures [35]. The synthesis route of PBI-R is shown in Scheme 1. The characterization data of R-PBI are shown in Figures S1-S6.

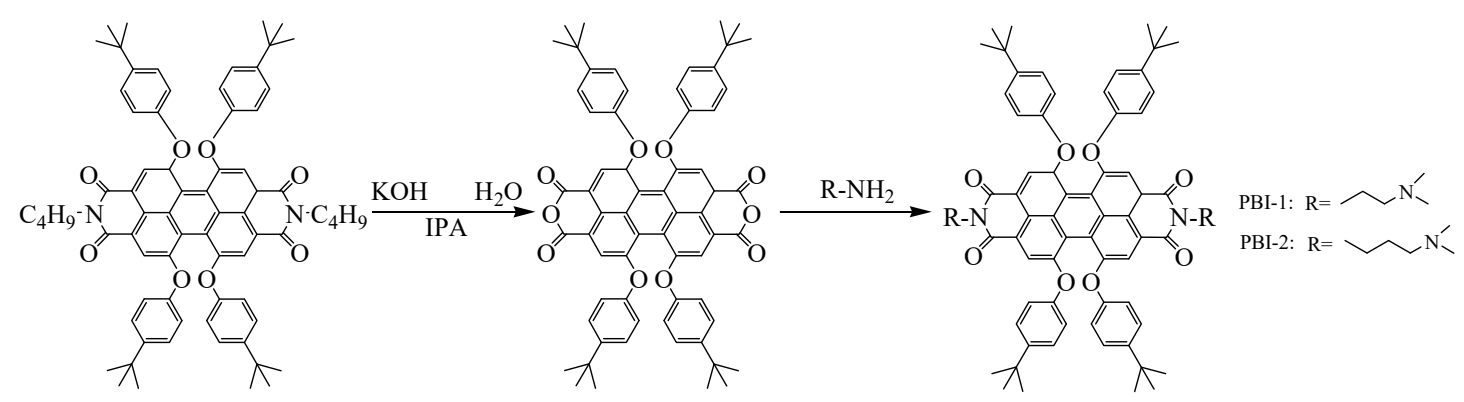

Scheme 1. Synthetic route of PBI-R. 


\subsubsection{Self-Assembly of PBI-R}

The self-assembly of PBI-R was performed by a rapid solution diffusion method [36], as shown in Scheme 2. To ensure that the concentration of PBI-R aggregates was $3 \times 10^{-5} \mathrm{~mol} / \mathrm{L}, 1 \mathrm{~mL}$ of $1.8 \times 10^{-4} \mathrm{~mol} / \mathrm{L}$ of PBI-R tetrahydrofuran solution (good solvent) was rapidly injected into $5 \mathrm{~mL}$ of acid solution (poor solvent). This mixture was allowed to stand for $24 \mathrm{~h}$ until it completely mixed. The p-toluenesulfonic acid, oxalic acid, malonic acid, citric acid, formic acid, glutaric acid and acetic acid were used in the self-assembly experiments. The ratio of $\mathrm{r}\left[\mathrm{c}\left(\mathrm{H}^{+}\right): \mathrm{c}(\right.$ the tertiary amine groups $\left.)\right]$ varied from 0:1 to 10,000:1 and 500:1 for PBI-1 and PBI-2, respectively (Table S1).

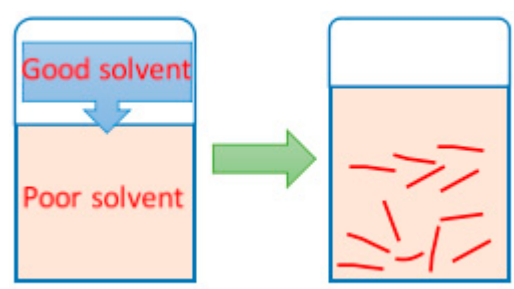

Scheme 2. Self-assembly procedure of PBI-R.

\subsection{Characterization}

Proton and carbon-13 nuclear magnetic resonance spectra of the samples were measured by INOVA-400 NMR analyzer (Varian, Inc, California, USA), and $\mathrm{CDCl}_{3}$ was used as solvent. FTIR spectra were recorded on a Nicolet-460 spectrometer (Thermo Fisher Scientific Inc, Massachusetts, USA) between 400 and $4000 \mathrm{~cm}^{-1}$ at room temperature by embedding the samples into $\mathrm{KBr}$ disks. The morphologies of the samples were characterized using a BX-51 polarized light microscope (Olympus Corporation, Tokyo, Japan). UV-vis absorption spectra were measured by a Shimadzu UV-2550 spectrometer (Shimadzu Corporation, Japan). Fluorescence spectra were recorded on a Hitachi F-2500 (Hitachi Corporation, Tokyo, Japan) spectrometer. X-ray diffraction (XRD) patterns were obtained on a Rigaku MiniFlex system with $\mathrm{Cu}-\mathrm{Ka}$ radiation. The diffraction intensity was measured in a $2 \theta$ range between $5^{\circ}$ and $90^{\circ}$ at a scanning rate of $0.01^{\circ} / \mathrm{s}$.

\section{Results and Discussion}

\subsection{Chemical Structures Dependence}

In previous studies [35], we demonstrated that the molecular structure can affect aggregation in hydrochloric acid. However, the situation in organic acids was not discussed; hence, we used a digital camera and UV-vis absorption spectroscopy to study the PBI-R aggregates. Figure 1 indicates that the color of the PBI-1 aggregates changed from red to blue on addition of the seven organic acids, except for the PBI-2 aggregates, which remained red. As shown in UV-vis absorption spectra (Figure 2), the red shift of the PBI- 2 aggregates was less than that of the PBI- 1 aggregates. The value of $\mathrm{A}_{0-0} / \mathrm{A}_{0-1}$ (the ratio of the $0-0$ to the $0-1$ transition) is related to the degree of aggregation. When $\mathrm{A}_{0-0} / \mathrm{A}_{0-1}$ was close to 1.6 , this indicated that the molecules existed in a single molecule state and that no aggregation occurred. The lower the value of $A_{0-0} / A_{0-1}$, the greater the degree of aggregation [30,37-39]. The $A_{0-0} / A_{0-1}$ of the PBI-R aggregates was calculated from the UV-vis absorption spectra; the $A_{0-0} / A_{0-1}$ of PBI- 1 aggregates was approximately 1.2 , whereas the $\mathrm{A}_{0-0} / \mathrm{A}_{0-1}$ of PBI-2 aggregates was approximately 0.9 . From the fluorescence emission spectrum (Figure 3), we can see that the Stokes shift of the PBI-2 aggregates is about $60 \mathrm{~nm}$ compared with the UV-vis absorption spectra, which is almost twice that of the PBI-1 aggregates. These results suggest that two types of molecular stacking modes occurred in the PBI-1 and PBI-2 aggregates. The reason for this might be that the PBI-2 molecule has three carbon atoms between the tertiary amine group and the core, and the protonated tertiary amine groups are far from the core plane. The charge repulsion interaction has a slight effect on PBI-2 molecular aggregation; hence, the intermolecular $\pi-\pi$ interactions of the PBI- 2 molecule are stronger. This study confirms that 
chemical structures have an important influence over the aggregation behavior in organic acids. Here, we will discuss the properties of PBI-1 aggregates assembled in various organic acids.

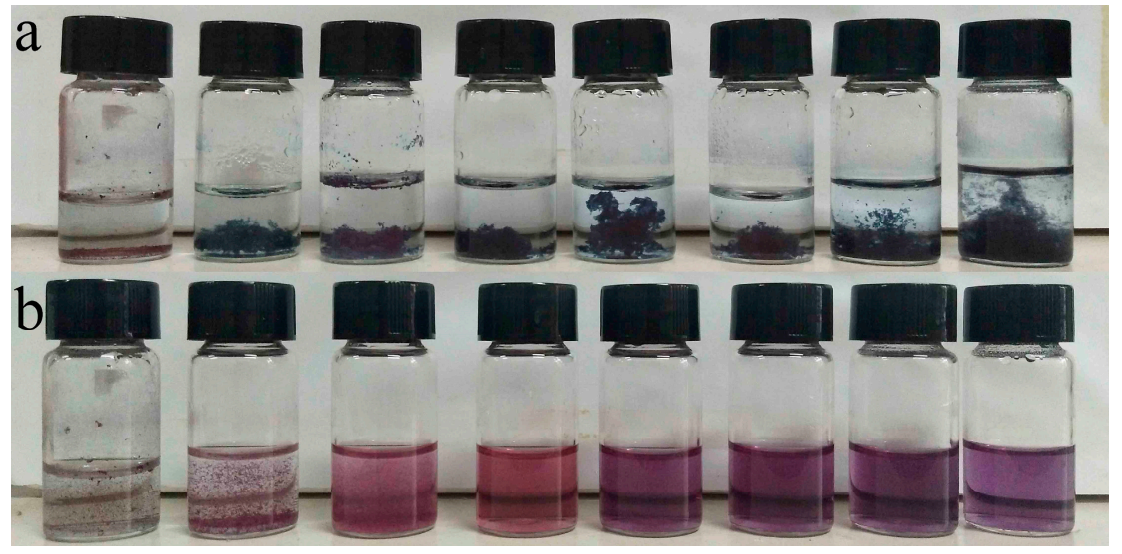

Figure 1. Digital images of PBI-R aggregates, $r=500: 1$, from left to right are water, p-toluenesulfonic acid, oxalic acid, malonic acid, citric acid, formic acid, glutaric acid and acetic acid. (a) PBI-1 and (b) PBI-2.
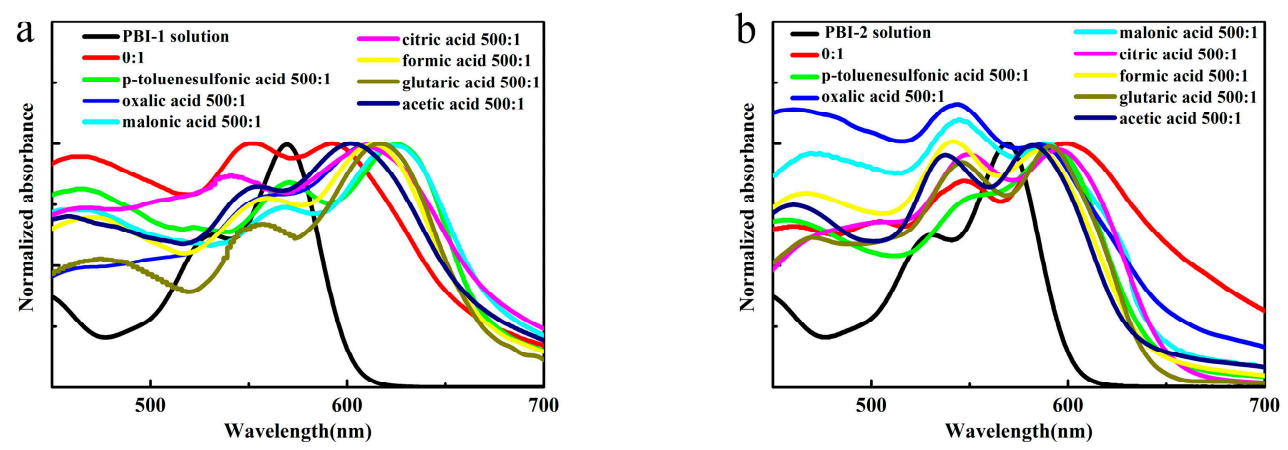

Figure 2. Normalized UV-visible (UV-vis) absorption spectra of PBI-R solution and PBI-R aggregates assembled in various organic acids. (a) PBI-1 and (b) PBI-2.
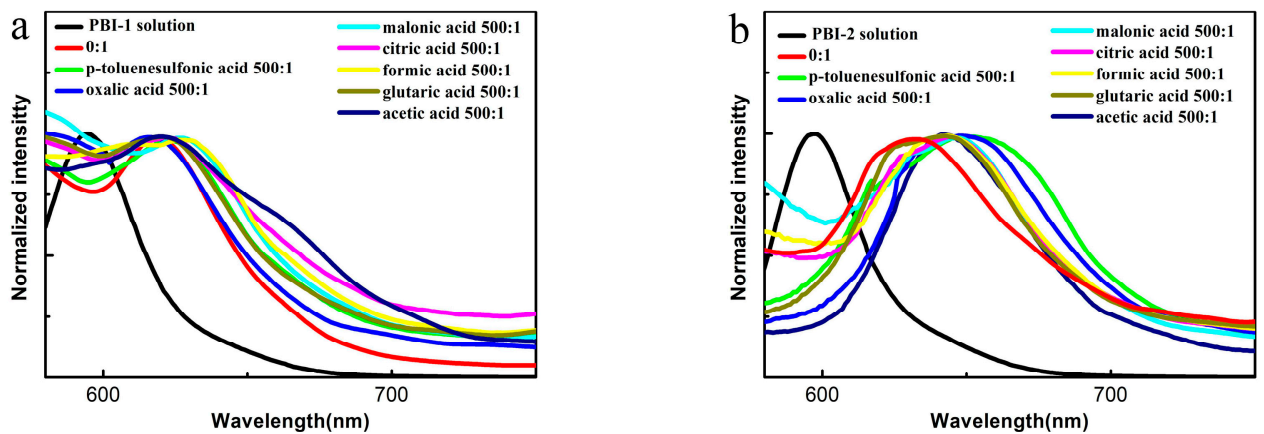

Figure 3. Normalized fluorescence emission spectrum of PBI-R solution and PBI-R aggregates assembled in various organic acids. (a) PBI-1 and (b) PBI-2.

\subsection{Morphologies of PBI-1 Aggregates}

Figure 4 shows a digital image of the PBI- 1 aggregates assembled in seven organic acids. The specific concentration of the organic acid changed the color of PBI-1 aggregates, that is, at $r=30: 1$ for p-toluenesulfonic acid, 50:1 for oxalic acid, 70:1 for malonic acid, 100:1 for citric acid, 200:1 for formic acid, 400:1 for glutaric acid and 500:1 for acetic acid. As shown in Table 1, p-toluenesulfonic acid is a strong organic acid with the lowest pKa among these seven organic acids. Hence, this acid is 
the strongest protonation agent and gives a sharp color change at a low $r$ value. We conclude that the $\mathrm{pKa}$ of the organic acids determines the $\mathrm{r}$ value of the color transition.

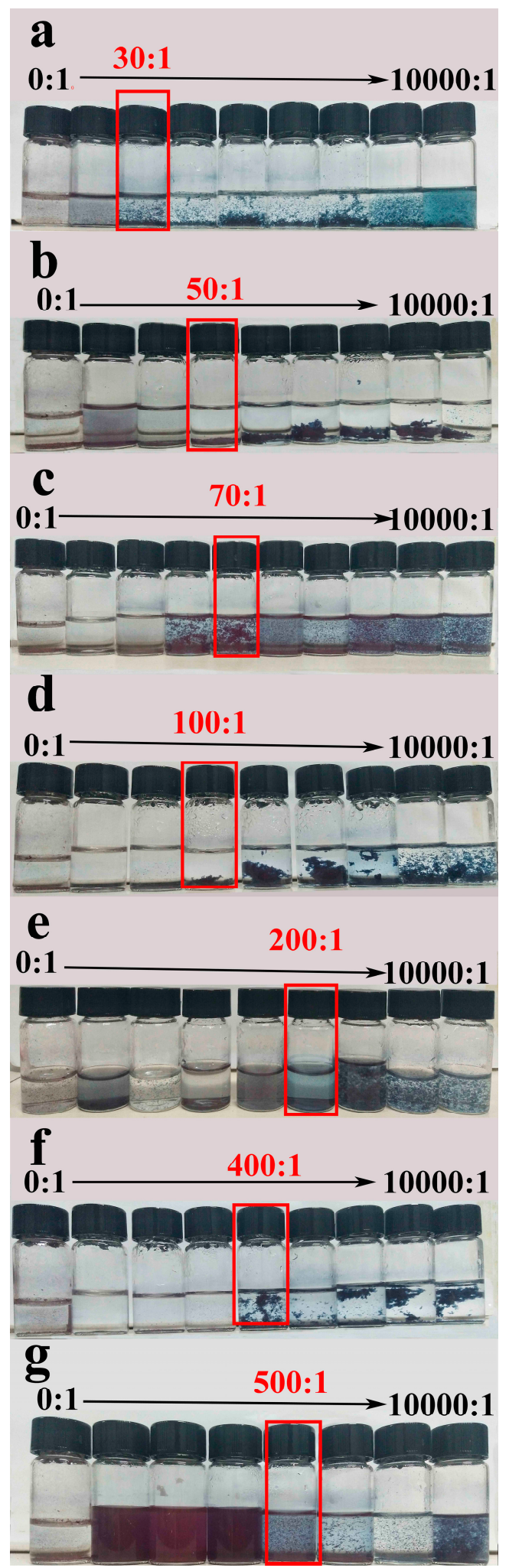

Figure 4. Digital image of PBI-1 aggregates assembled in various organic acids corresponding to different $r$ values, from 0:1 to 10,000:1. (a) p-Toluenesulfonic acid, (b) oxalic acid, (c) malonic acid, (d) citric acid, (e) formic acid, (f) glutaric acid and (g) acetic acid. 
Table 1. pKa values of several organic acids.

\begin{tabular}{ccccccccc}
\hline $\begin{array}{c}\text { p-Toluenesulfonic } \\
\text { Acid }\end{array}$ & $\begin{array}{c}\text { Oxalic } \\
\text { Acid }\end{array}$ & $\begin{array}{c}\text { Malonic } \\
\text { Acid }\end{array}$ & $\begin{array}{c}\text { Citric } \\
\text { Acid }\end{array}$ & $\begin{array}{c}\text { Formic } \\
\text { Acid }\end{array}$ & $\begin{array}{c}\text { Glutaric } \\
\text { Acid }\end{array}$ & $\begin{array}{c}\text { Acetic } \\
\text { Acid }\end{array}$ & $\begin{array}{c}\text { Adipic } \\
\text { Acid }\end{array}$ \\
\hline $\mathrm{pKa}$ & $-0.43 \pm 0.50$ & 1.23 & 2.83 & 3.14 & 3.75 & 4.31 & 4.74 & 4.43 \\
\hline
\end{tabular}

Morphologies of PBI-1 aggregates assembled in various organic acids were observed in detail with the use of POM (Figures 5 and 6) and SEM (Figure 7). As shown in Figure 5, when $r=0: 1$, that is, without organic acid, PBI-1 assembled into massive irregular aggregates. After p-toluenesulfonic acid was added, the fine fibers began to grow. The number of fibers increased, and they lengthened as the $r$ value increased. The same results (Figure S7) were observed in oxalic acid, malonic acid, citric acid, formic acid, glutaric acid and acetic acid. It is likely that in the presence of only water, the driving forces of self-assembly are $\pi-\pi$ stacking and hydrophobic interaction; hence, PBI- 1 molecules will assemble quickly by hydrophobic interactions. At this time, $\pi-\pi$ stacking is too slow to make PBI-1 molecules completely align in a certain direction, which results in irregular aggregates [34]. After the organic acid was added, the organic acid ionized to generate $\mathrm{H}^{+}$, protonating the tertiary amine. The protonated tertiary amine groups induce charge repulsion interactions and $\pi-\pi$ stacking interactions on PBI-1 molecules in addition to hydrophobic interactions. The degree of protonation of the tertiary amine groups increased as $r$ increased, which is more conducive to an ordered arrangement; hence, the fibers lengthened.

As shown in Figures 6 and 7, fibers in dibasic and tribasic acids were shorter than those in monobasic acids. The molecular structure of the organic acid anions also affected the self-assembly process. Oxalic acid, malonic acid and glutaric acid are dibasic acids; one diacid molecule might be connected to two PBI-1 molecules during ionization, which limits the ordered arrangement of molecules (Figure 8); hence, only short fibers can be formed. Similarly, tribasic acid and citric acid can only form short fibers. In addition, there are some changes in the molecular stacking direction owing to charge repulsion interactions, which induce the formation of curved fibers.

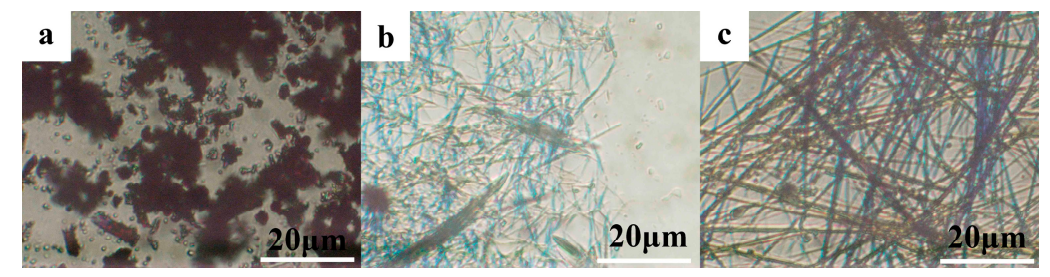

Figure 5. Optical microscope images of PBI-1 aggregates assembled in p-toluenesulfonic acid. (a) $r=0: 1$, (b) $r=50: 1$ and (c) $r=10,000: 1$.

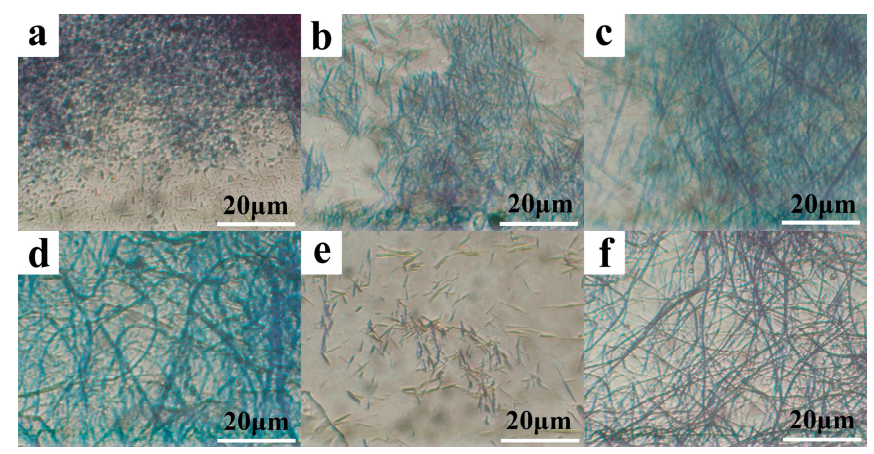

Figure 6. Optical microscope images of PBI-1 aggregates assembled in various organic acids. (a) $r=10,000: 1$ oxalic acid, (b) $r=5000: 1$ malonic acid, (c) $r=10,000: 1$ citric acid, (d) $r=10,000: 1$ formic acid, (e) $r=10,000: 1$ glutaric acid and (f) $r=5000: 1$ acetic acid. 


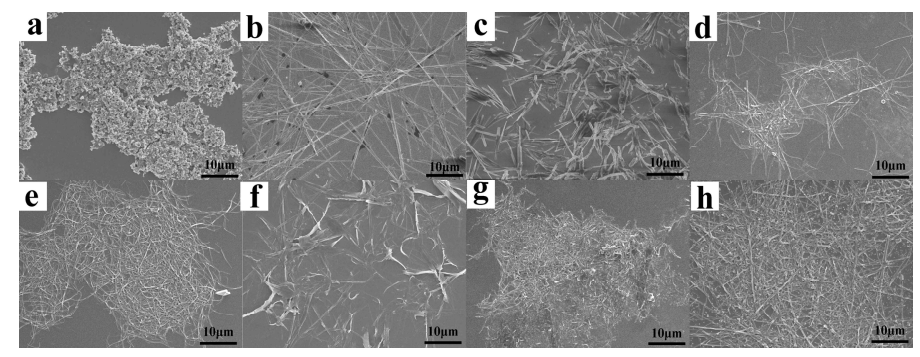

Figure 7. Scanning electron microscopy (SEM) images of PBI-1 aggregates assembled in various organic acids, $r=5000: 1$. (a) No added acid, (b) p-toluenesulfonic acid, (c) oxalic acid, (d) malonic acid, (e) citric acid, (f) formic acid, (g) glutaric acid and (h) acetic acid.

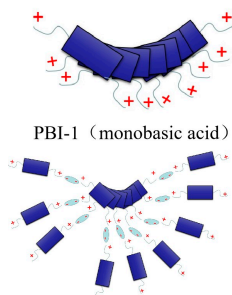

PBI-1 (dibasic acid)

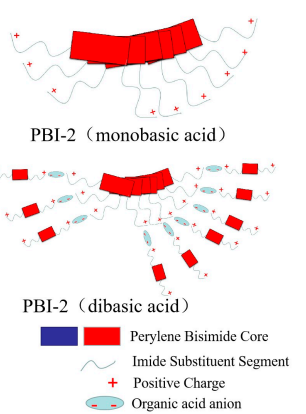

Figure 8. Proposed schematic diagrams of self-assembly for PBI-1 and PBI-2.

From the above results, we concluded that both the degree of protonation of the tertiary amine group and molecular structures of organic acids have considerable effects on the structure of PBI-1 aggregates, which is because the kinds and concentrations of organic acids lead to different driving forces in the self-assembly process.

\subsection{Photophysical Properties of PBI-1 Aggregates}

To further explore the effects of organic acids on the photophysical properties of PBI-1 aggregates, we performed UV-vis absorption spectroscopy and fluorescence emission spectroscopy of PBI-1 aggregates. Figure 9 shows the normalized UV-vis absorption spectrum of PBI-1 solution and a part of the PBI-1 aggregates in different assembly conditions. The UV-vis absorption spectrum of PBI-1 in THF solution had three absorption peaks at 440, 530 and $570 \mathrm{~nm}$, which represent 0-2, 0-1 and 0-0 electron transitions, respectively [25,40-42]. When $r=0: 1$, the maximum UV-vis absorption peak of the PBI-1 aggregates red-shifted from 570 to $590 \mathrm{~nm}$ compared with PBI-1 solution. After adding organic acid, the red shift increased. For the same organic acid, the red shift increased as the $r$ value increased. When $r$ increased from 0:1 to 1000:1, the red shift of PBI-1 aggregates assembled in p-toluenesulfonic acid (Figure 9a) was the largest, which is approximately $40 \mathrm{~nm}$ compared with that of no organic acid. The red shifts of the PBI-1 aggregates assembled in oxalic acid, malonic acid and citric acid were approximately $35 \mathrm{~nm}$ (Figure $9 \mathrm{~b}-\mathrm{d}$ ), that in formic acid was approximately $30 \mathrm{~nm}$ (Figure 9e) and those in glutaric acid and acetic acid were approximately $25 \mathrm{~nm}$ (Figure 9f,g). Additionally, after adding the organic acid, the $A_{0-0} / A_{0-1}$ value was markedly lowered. The values of $A_{0-0} / A_{0-1}$ for $p$-toluenesulfonic acid, oxalic acid, malonic acid, citric acid, formic acid, glutaric acid and acetic acid were approximately $1.19,1.21,1.26,1.29,1.31,1.32$ and 1.32, respectively (Table S2). The UV-vis spectra indicated that the $\pi-\pi$ interaction was greatest in acetic acid owing to its minimal red shift $[43,44]$. The molecular stacking mode of the aggregates was J-type aggregation. This is because charge repulsion interactions increase as $r$ increases and the pKa decreases; hence, $\pi-\pi$ interactions decrease. The PBI- 1 molecular bay positions are replaced by tert-butylphenoxy groups, which have a large steric hindrance that destroys the planarity of the PBI molecules; hence, PBI-1 molecules aggregate in a J-type manner when 
stacked $[45,46]$. The above results indicate that the degree of protonation has notable effects on the photophysical properties of PBI-1 aggregates.
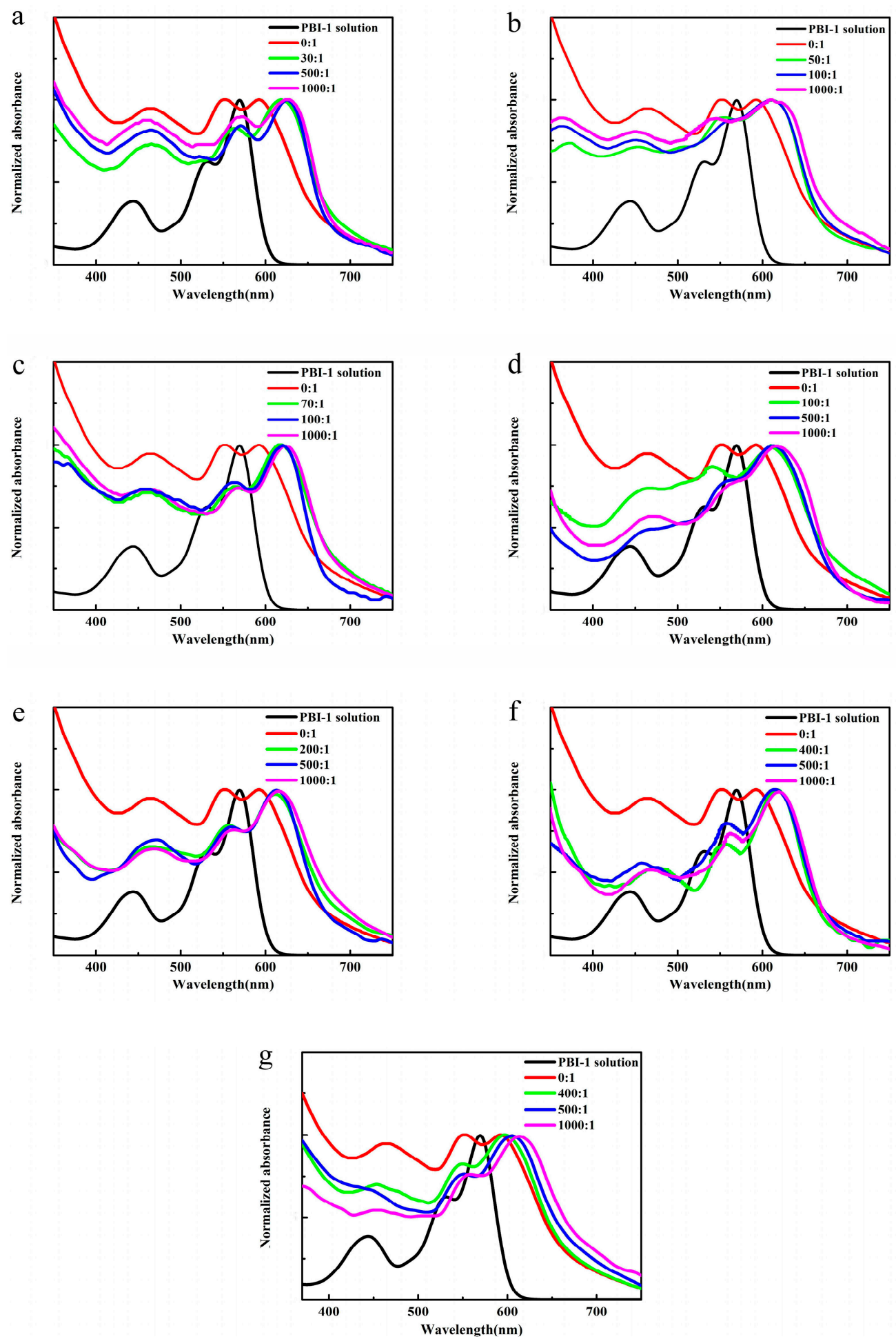

Figure 9. Normalized UV-vis absorption spectra of PBI-1 solution and PBI-1 aggregates at different $r$ values assembled in various organic acids. (a) p-Toluenesulfonic acid, (b) oxalic acid, (c) malonic acid, (d) citric acid, (e) formic acid, (f) glutaric acid and (g) acetic acid.

Figure 10 shows the normalized fluorescence emission spectrum of PBI-1 solution and a part of the PBI-1 aggregated under the different assembly conditions. The fluorescence emission spectrum of 
PBI-1 solution had an emission peak at approximately $595 \mathrm{~nm}$ and a Stokes shift of approximately $25 \mathrm{~nm}$. The fluorescence emission spectrum of the PBI-1 aggregates assembled in organic acid solution had a maximum emission peak at 620-640 nm. Additionally, the bathochromic shift of the emission peak increased as $r$ increased and the $\mathrm{pK}_{\mathrm{a}}$ decreased, which is consistent with the results of the UV-vis absorption spectra. The formation of J-aggregates can be further confirmed by a bathochromic shift of fluorescence emission peak [27,47]. The fluorescence of the PBI-1 aggregates was not quenched, which might be attributable to the charge repulsion interaction provided by protonated tertiary amine groups, which weakened the molecular $\pi-\pi$ interactions; hence, the aggregates retained their fluorescence.
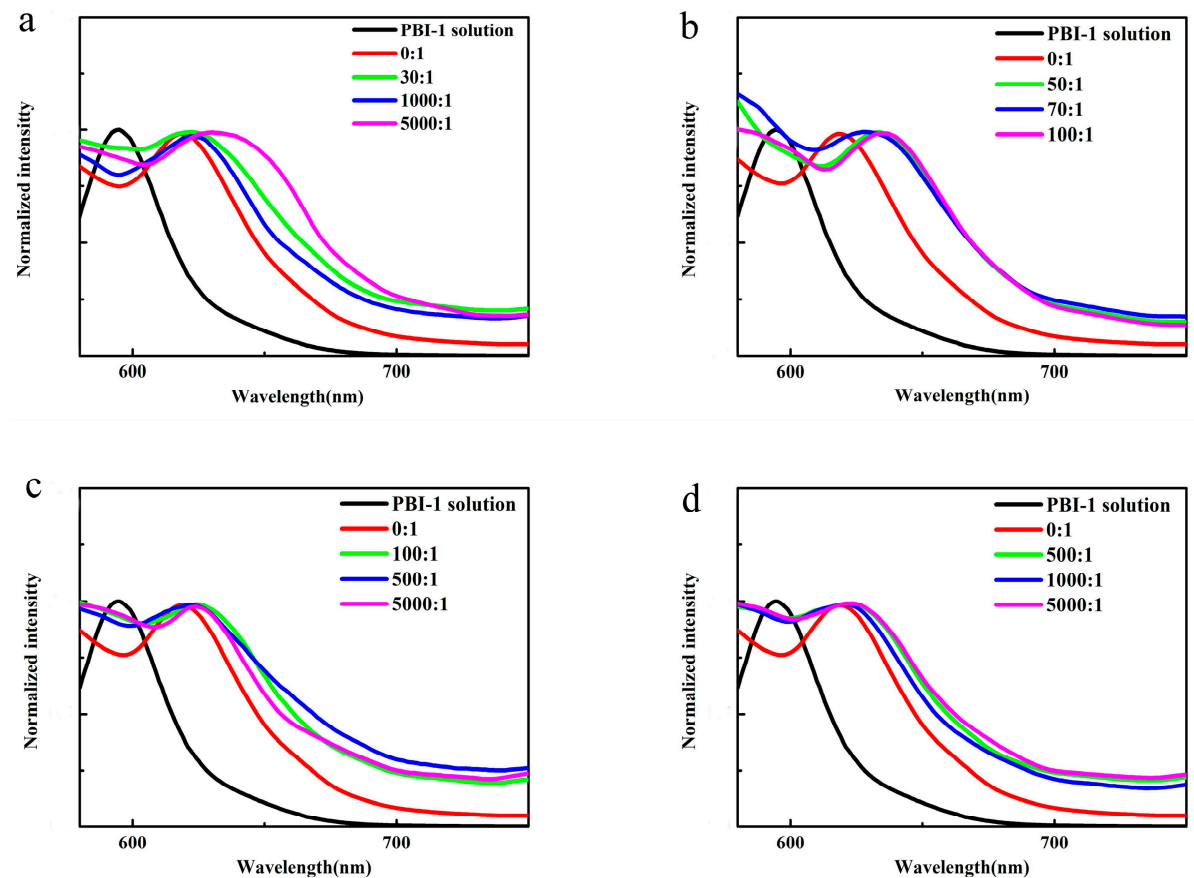

Figure 10. Normalized fluorescence emission spectra of PBI-1 solution and PBI-1 aggregates at different $r$ values assembled in various organic acids. (a) p-Toluenesulfonic acid, (b) oxalic acid, (c) citric acid and (d) glutaric acid. $\lambda_{\mathrm{ex}}=440 \mathrm{~nm}$ was used to record the emission spectra.

\subsection{Molecular Stacking of PBI-1 Aggregates}

To further study the internal structure of PBI-1 aggregates, XRD was performed on PBI-1 powder and partial aggregates (Figure 11). As can be seen from Figure 11a, the PBI-1 powder had a diffraction peak at $2 \theta=5.76^{\circ}(1.53 \mathrm{~nm})$, which corresponds to the (100) plane and can be assigned to the lengths of the PBI-1 units [8]. The low-intensity diffraction peak appearing at $2 \theta=22.4^{\circ}(0.39 \mathrm{~nm})$ is attributed to $\pi-\pi$ stacking of adjacent PBI- 1 molecules, which indicates that the $\pi-\pi$ stacking effect is weak $[48,49]$. The diffraction peak of PBI-1 aggregates at $22.76^{\circ}(0.39 \mathrm{~nm})$ broadens to form a taro peak when $r=0: 1$ (Figure 11b), which indicates that the $\pi-\pi$ stacking effect strengthens $[48,50]$. In addition to the $\pi-\pi$ stacking peak of $0.40 \mathrm{~nm}$, the $\mathrm{d}$ values of the three diffraction peaks become greater for the p-toluenesulfonic acid system, and the d value increased from 1.56 to $1.58 \mathrm{~nm}$ when $\mathrm{r}$ increased from 30:1 to 100:1 (Figure 11c,d); whereas the diffraction peak was basically the same as $r=0: 1$ in the wide-angle region for formic acid and acetic acid system, and the $\mathrm{d}$ value of the diffraction peak in the small angle region decreased (Figure 11e,f). Hence, there are some notable differences in the self-assembly process of PBI-1 molecules by XRD. This result is consistent with information obtained from the UV-vis absorption spectra. 

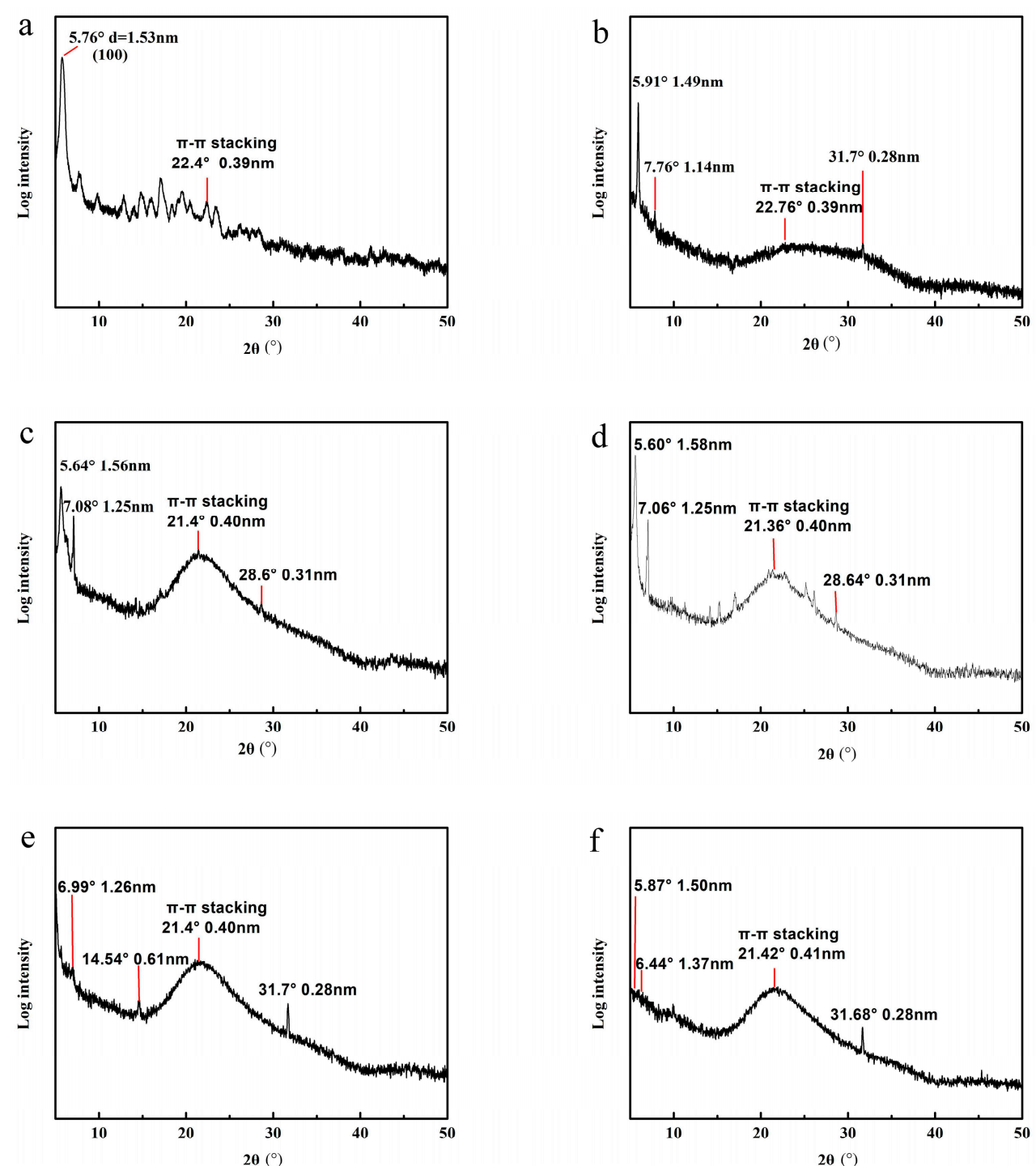

Figure 11. X-ray diffraction (XRD) of PBI-1 powder and partial aggregates. (a) PBI-1 powder, (b) $r=0: 1$, (c) $r=30: 1$ p-toluenesulfonic acid, (d) $r=100: 1$ p-toluenesulfonic acid, (e) $r=200: 1$ formic acid and (f) $\mathrm{r}=500: 1$ acetic acid.

\subsection{Thermal Sensitivity of PBI-1 Aggregates}

To investigate the thermal sensitivity of PBI-1 aggregates, UV-vis absorption spectra of the heated aggregates were measured. As shown in Figure 12, when the temperature of aggregates was gradually increased to $120^{\circ} \mathrm{C}$ and held for $2 \mathrm{~h}$, the UV-vis absorption spectra did not change in hydrochloric acid (Figure 12a), p-toluenesulfonic acid (Figure 12b), formic acid (Figure S8b) or acetic acid (Figure S8c); the UV-vis absorption spectra blue-shifted in oxalic acid (Figure S8a), malonic acid (Figure 12c), glutaric acid (Figure 12e) and citric acid (Figure 12d) by approximately 7, 10, 20 and $10 \mathrm{~nm}$, respectively. The color of the aggregates formed in glutaric acid changed from blue to red after heating at $120^{\circ} \mathrm{C}$ for $2 \mathrm{~h}$ (Figure 13a). At the same time, we also confirmed that the same phenomenon exists in the aggregates formed in the adipic acid (Figure S9, Figures $12 \mathrm{f}$ and $13 \mathrm{~b}$ ). These results indicate that PBI-1 aggregates formed in dibasic and tribasic acids are sensitive to temperature.

Reasonable explanations for these observations are that charge repulsion interactions and the large steric hindrance reduced the overlapping area of aromatic rings of adjacent PBI-1 molecules in dibasic and tribasic acids, such that $\pi-\pi$ interactions were weaker than those in monobasic acids. Therefore, UV-vis absorption spectra of aggregates formed in dibasic and tribasic acids blue-shifted 
after heating. Among these, glutaric acid has a relatively flexible alkyl chain, which is conducive to molecule movement. Therefore, aggregates formed in glutaric acid had the maximum blue shift after heating.
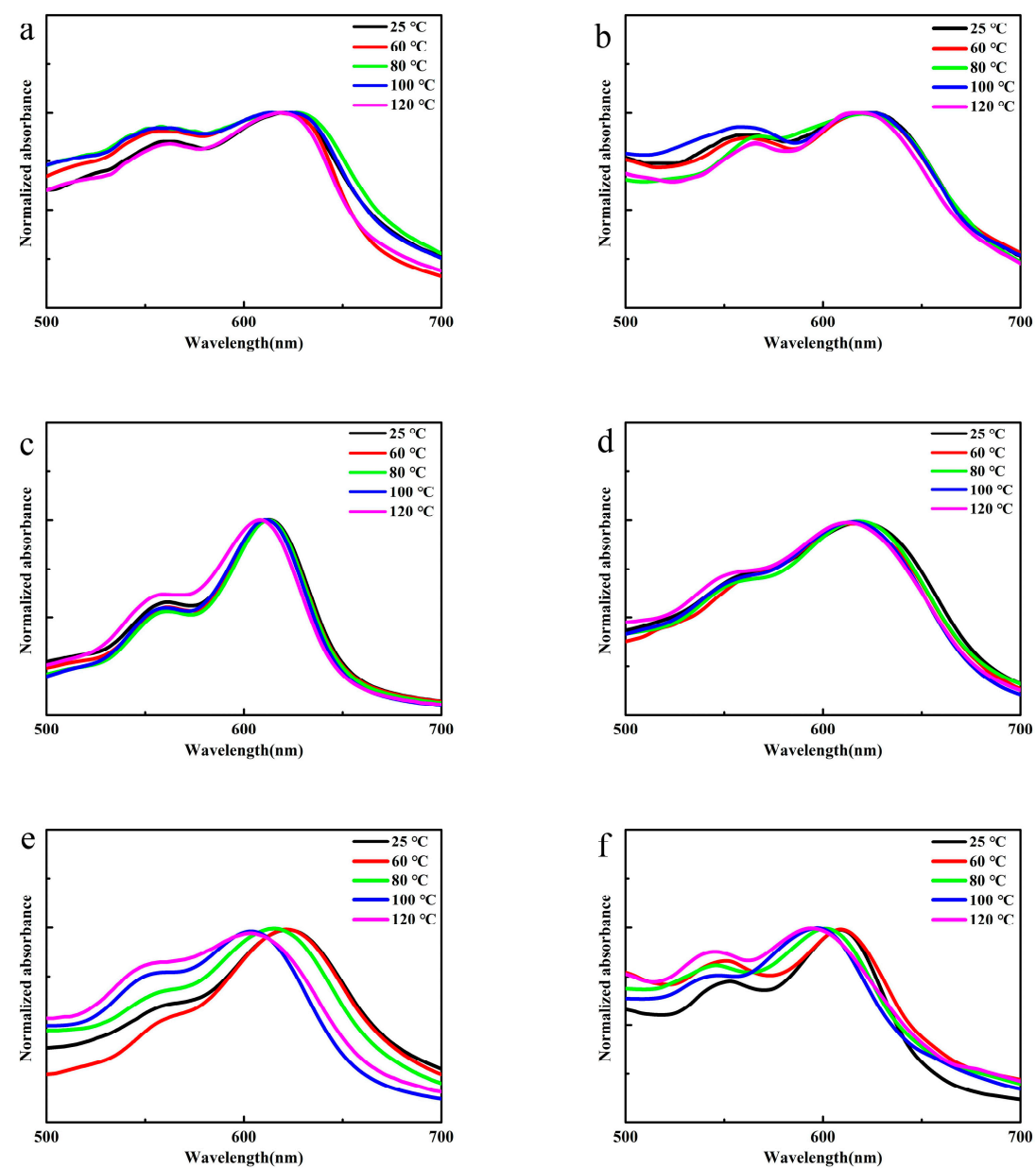

Figure 12. Normalized UV-vis absorption spectra of PBI-1 aggregates after $2 \mathrm{~h}$ heating. (a) $\mathrm{r}=15: 1$ hydrochloric acid, (b) $r=30: 1$ p-toluenesulfonic acid, (c) $r=100: 1$ malonic acid, (d) $r=200: 1$ citric acid, (e) $r=500: 1$ glutaric acid and (f) $r=500: 1$ adipic acid.
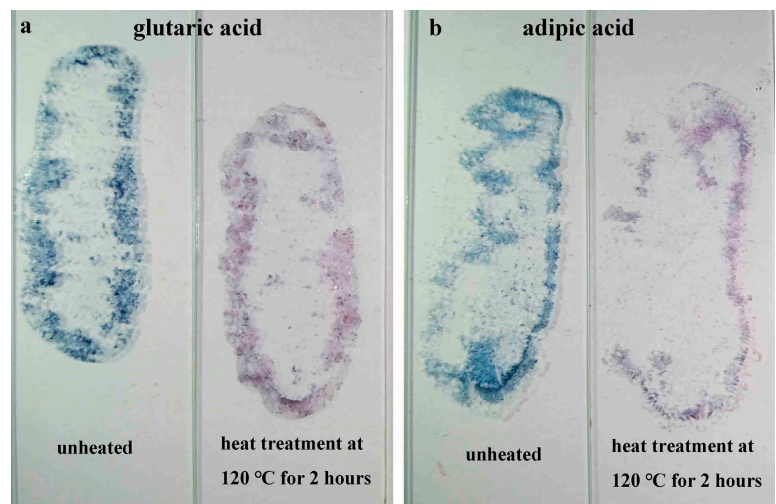

Figure 13. Digital image of PBI-1 aggregates, $r=500: 1$.

\subsection{Gas Sensitivity of PBI-1 Aggregates}

To investigate the gas sensitivity of PBI-1 aggregates, ammonia-treated aggregates were characterized using UV-vis absorption spectroscopy. As shown in Figure 14a,b, UV-vis absorption 
spectra of the PBI-1 aggregates blue-shifted after the ammonia treatment at the same $r$ value, and the blue shift gradually increased as treatment time increased. In the p-toluenesulfonic acid system, the blue shift became approximately $15 \mathrm{~nm}$ as the treatment time was increased from 0 to $10 \mathrm{~min}$. Figure $14 \mathrm{c}-\mathrm{h}$ indicates that the blue shift gradually increased as the treatment temperature increased for the same ammonia treatment time. For example, the UV-vis absorption spectrum blue-shifted by $25 \mathrm{~nm}$ when the temperature was raised to $80^{\circ} \mathrm{C}$ for the p-toluenesulfonic acid system; for the oxalic acid system, the blue shift was approximately $15 \mathrm{~nm}$; for the malonic acid, citric acid and glutaric acid systems, the blue shifts were approximately $7 \mathrm{~nm}$. The UV-vis absorption spectrum did not change in the formic acid system.
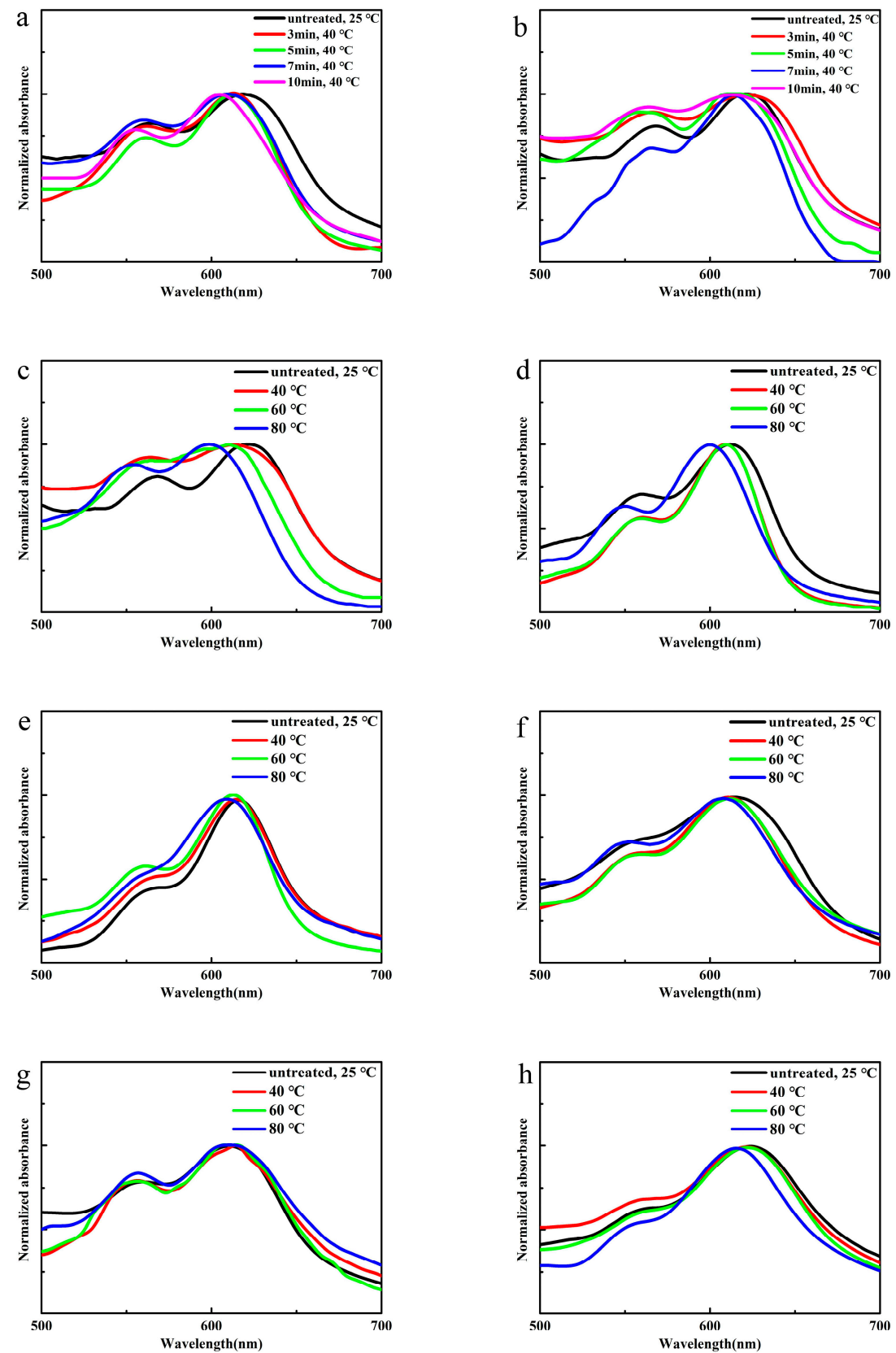

Figure 14. Normalized UV-vis absorption spectra of PBI-1 aggregates with ammonia treatment. (a) $\mathrm{r}=30: 1$ p-toluenesulfonic acid, $40{ }^{\circ} \mathrm{C}$, (b) $\mathrm{r}=50: 1 \mathrm{p}$-toluenesulfonic acid, $40{ }^{\circ} \mathrm{C}$, (c) $\mathrm{r}=50: 1$ p-toluenesulfonic acid, $10 \mathrm{~min},(\mathbf{d}) \mathrm{r}=50: 1$ oxalic acid, $10 \mathrm{~min},(\mathbf{e}) \mathrm{r}=100: 1$ malonic acid, $10 \mathrm{~min}$, (f) $r=200: 1$ citric acid, $10 \mathrm{~min},(\mathrm{~g}) \mathrm{r}=500: 1$ formic acid, $10 \mathrm{~min}$ and (h) $\mathrm{r}=$ 500:1 glutaric acid, $10 \mathrm{~min}$. 
This phenomenon might be attributable to ammonia gas reacting with protonated tertiary amine groups, which changes the aggregation of PBI-1 aggregates and the maximum absorption blue shift. The reaction proceeded to completion as the temperature was increased and the time prolonged, which led to a greater blue shift.

\section{Conclusions}

In summary, we designed and synthesized PBI-1 and PBI-2 molecules with tertiary amine substituents. The color of the PBI- 1 aggregates changed from red to blue after addition of seven organic acids, and the color of PBI-2 aggregates remained red. We have demonstrated that protonation of tertiary amine groups and the anionic structure of organic acids affect the aggregation of PBI- 1 . The charge repulsion interactions provided by organic acids synergistically interact with other non-covalent bonding forces to transform irregular PBI-1 aggregates into well-defined nanofibers. The preparation method is simple, and morphologies, colors and photophysical properties are controllable. Additionally, the system has a certain sensitivity to temperature and ammonia, which suggests the potential for application of PBI-1 aggregates in optoelectronic devices or sensors.

Supplementary Materials: The following are available online at http://www.mdpi.com/1996-1944/13/7/1656/s1, Figure S1: 1H NMR spectrum of PBI-1 in CDC13, Figure S2: 13C NMR spectrum of PBI-1 in CDCl3, Figure S3: FT-IR spectrum of PBI-1, Figure S4: 1H NMR spectrum of PBI-2 in CDCl3, Figure S5: 13C NMR spectrum of PBI-2 in CDCl3, Figure S6: FT-IR spectrum of PBI-2, Figure S7: Optical microscope images of PBI-1 aggregates at different $\mathrm{r}$ assembled in various organic acids, Figure S8: Normalized UV-vis absorption spectra of PBI-1 aggregates after 2 $\mathrm{h}$ heating. (a) $\mathrm{r}=50: 1$ oxalic acid, (b) $\mathrm{r}=300: 1$ formic acid, (c) $\mathrm{r}=500: 1$ acetic acid, Figure S9: Digital image of PBI-1 aggregates assembled in adipic acid, $r=500: 1$, Table S1: Organic acid concentrations correspond to different $r$ parameters, Table S2: The value of $\mathrm{A}_{0-0} / \mathrm{A}_{0-1}$ of PBI- 1 aggregates at different $\mathrm{r}$ assembled in various organic acids.

Author Contributions: All authors discussed and agreed upon the idea, and made scientific contributions: writing-original draft preparation, Y.W.; experimental design, Y.W. and S.L.; practical experimentation, Y.W. and T.L.; data analysis, Y.W.; writing-review and editing, X.Y. and W.L. All authors have read and agreed to the published version of the manuscript.

Funding: This work was supported by the National Natural Science Foundation of China (Grants 50573019 and 51273061) and the Hunan Natural Science Foundation (Grant 2016JJ2027).

Conflicts of Interest: The authors declare no conflicts of interest.

\section{References}

1. Mateos-Timoneda, M.A.; Crego-Calama, M.; Reinhoudt, D.N. Supramolecular chirality of self-assembled systems in solution. Chem. Soc. Rev. 2004, 33, 363-372. [CrossRef] [PubMed]

2. Tang, T.; Qu, J.; Müllen, K.; Webber, S.E. Molecular layer-by-layer self-assembly of water-soluble perylene diimides through $\pi-\pi$ and electrostatic interactions. Langmuir 2006, 22, 26-28. [CrossRef] [PubMed]

3. Willerich, I.; Gröhn, F. Molecular structure encodes nanoscale assemblies: Understanding driving forces in electrostatic self-assembly. J. Am. Chem. Soc. 2011, 133, 20341-20356. [CrossRef]

4. Sukul, P.K.; Asthana, D.; Mukhopadhyay, P.; Summa, D.; Muccioli, L.; Zannoni, C.; Beljonne, D.; Rowan, A.E.; Malik, S. Assemblies of perylene diimide derivatives with melamine into luminescent hydrogels. Chem. Commun. 2011, 47, 11858-11860. [CrossRef] [PubMed]

5. Tuccitto, N.; Delfanti, I.; Torrisi, V.; Scandola, F.; Chiorboli, C.; Stepanenko, V.; Würthner, F.; Licciardello, A. Supramolecular self-assembled multilayers of terpyridine-functionalized perylene bisimide metal complexes. Phys. Chem. Chem. Phys. 2009, 11, 4033-4038. [CrossRef] [PubMed]

6. Chen, Z.; Fimmel, B.; Würthner, F. Solvent and substituent effects on aggregation constants of perylene bisimide $\pi$-stacks-a linear free energy relationship analysis. Org. Biomol. Chem. 2012, 10, 5845-5855. [CrossRef] [PubMed]

7. Chen, S.; Slattum, P.; Wang, C.; Zang, L. Self-assembly of perylene imide molecules into 1D nanostructures: Methods, morphologies, and applications. Chem. Rev. 2015, 115, 11967-11998. [CrossRef]

8. Zhang, F.; Ma, Y.; Chi, Y.; Yu, H.; Li, Y.; Jiang, T.; Wei, X.; Shi, J. Self-assembly, optical and electrical properties of perylene diimide dyes bearing unsymmetrical substituents at bay position. Sci. Rep. 2018, 8, 1-11. [CrossRef] 
9. Ma, W.; Luo, Y.; Nian, L.; Wang, J.; Wen, X.; Liu, L.; Hanif, M.; Xie, Z.; Ma, Y. Construction of layered structure of anion-cations to tune the work function of aluminum-doped zinc oxide for inverted polymer solar cells. Acs Appl. Mater. Interfaces 2018, 10, 10513-10519. [CrossRef]

10. Yu, C.; Xu, Y.; Liang, S.; Jiang, X.; Feng, G.; Li, C.; Li, W. Ethynyl-linked perylene bisimide based electron acceptors for non-fullerene organic solar cells. Chin. Chem. Lett. 2018, 29, 325-327. [CrossRef]

11. Regar, R.; Mishra, R.; Singhal, R.; Sharma, G.D.; Sankar, J. NIR absorbing ortho- $\pi$-extended perylene bisimide as a promising material for bulk heterojunction organic solar cells. J. Mater. Chem. A 2019, 7, 3012-3017. [CrossRef]

12. Xia, D.; Li, C.; Li, W. Crystalline conjugated polymers for organic solar cells: From donor, acceptor to single-component. Chem. Rec. 2019, 19, 962-972. [CrossRef] [PubMed]

13. Singh, T.B.; Erten, S.; Günes, S.; Zafer, C.; Turkmen, G.; Kuban, B.; Teoman, Y.; Sariciftci, N.; Icli, S. Soluble derivatives of perylene and naphthalene diimide for n-channel organic field-effect transistors. Org. Electron. 2006, 7, 480-489. [CrossRef]

14. Gawrys, P.; Boudinet, D.; Zagorska, M.; Djurado, D.; Verilhac, J.-M.; Horowitz, G.; Pécaud, J.; Pouget, S.; Pron, A. Solution processible naphthalene and perylene bisimides: Synthesis, electrochemical characterization and application to organic field effect transistors (OFETs) fabrication. Synth. Met. 2009, 159, 1478-1485. [CrossRef]

15. Cherpak, V.; Stakhira, P.; Volynyuk, D.; Politanskiy, L.; Kus, N.; Reghu, R.; Grazulevicius, J. Ambipolar conductivity in organic field-effect transistors based on 1, 7-bis (9-ethyl-3-carbazolyl) N, N'-2-ethyl hexyl perylene bisimide under the light illumination. Opt. Mater. 2014, 36, 1511-1514. [CrossRef]

16. Kucinska, M.; Frac, I.; Ulanski, J.; Makowski, T.; Nosal, A.; Gazicki-Lipman, M. The role of surface morphology in a performance of top-gate OFETs prepared from a solution processable derivative of perylene bisimide. Synth. Met. 2019, 250, 12-19. [CrossRef]

17. Tsai, H.-Y.; Chen, K.-Y. Synthesis and optical properties of novel asymmetric perylene bisimides. J. Lumin. 2014, 149, 103-111. [CrossRef]

18. Kozma, E.; Mróz, W.; Galeotti, F. A polystyrene bearing perylene diimide pendants with enhanced solid state emission for white hybrid light-emitting diodes. Dye. Pigment. 2015, 114, 138-143. [CrossRef]

19. Zong, L.; Gong, Y.; Yu, Y.; Xie, Y.; Xie, G.; Peng, Q.; Li, Q.; Li, Z. New perylene diimide derivatives: Stable red emission, adjustable property from ACQ to AIE, and good device performance with an EQE value of $4.93 \%$. Sci. Bull. 2018, 63, 108-116. [CrossRef]

20. Yan, L.; Ye, Z.; Peng, C.; Zhang, S. A new perylene diimide-based fluorescent chemosensor for selective detection of ATP in aqueous solution. Tetrahedron 2012, 68, 2725-2727. [CrossRef]

21. Pramanik, B.; Mondal, J.H.; Singha, N.; Ahmed, S.; Mohanty, J.; Das, D. A Viologen-perylenediimide conjugate as an efficient base sensor with solvatochromic property. Chem. Phys. Chem. 2017, 18, 245-252. [CrossRef] [PubMed]

22. Ye, F.; Liang, X.-M.; Wu, N.; Li, P.; Chai, Q.; Fu, Y. A new perylene-based fluorescent $\mathrm{pH}$ chemosensor for strongly acidic condition. Spectrochim. Acta Part. A Mol. Biomol. Spectrosc. 2019, 216, 359-364. [CrossRef] [PubMed]

23. Zhu, P.; Wang, Y.; Ma, P.; Li, S.; Fan, F.; Cui, K.; Ge, S.; Zhang, Y.; Yu, J. Low-power and high-performance trimethylamine gas sensor based on $n$ heterojunction microbelts of perylene diimide/CdS. Anal. Chem. 2019, 91, 5591-5598. [CrossRef]

24. Sukul, P.K.; Datta, A.; Malik, S. Light harvesting and amplification of emission of donor perylene-acceptor perylene aggregates in aqueous medium. Chem. A Eur. J. 2014, 20, 3019-3022. [CrossRef] [PubMed]

25. Balakrishnan, K.; Datar, A.; Naddo, T.; Huang, J.; Oitker, R.; Yen, M.; Zhao, J.; Zang, L. Effect of side-chain substituents on self-assembly of perylene diimide molecules: Morphology control. J. Am. Chem. Soc. 2006, 128, 7390-7398. [CrossRef] [PubMed]

26. Yang, X.; Xu, X.; Ji, H.-F. Solvent effect on the self-assembled structure of an amphiphilic perylene diimide derivative. J. Phys. Chem. B 2008, 112, 7196-7202. [CrossRef]

27. Ke, D.; Zhan, C.; Xu, S.; Ding, X.; Peng, A.; Sun, J.; He, S.; Li, A.D.; Yao, J. Self-assembled hollow nanospheres strongly enhance photoluminescence. J. Am. Chem. Soc. 2011, 133, 11022-11025. [CrossRef]

28. Ariga, K.; Hill, J.P.; Lee, M.V.; Vinu, A.; Charvet, R.; Acharya, S. Challenges and breakthroughs in recent research on self-assembly. Sci. Technol. Adv. Mater. 2008, 9, 014109. [CrossRef] 
29. Cui, L.; Jiao, Y.; Wang, A.; Zhao, L.; Dong, Q.; Yan, X.; Bai, S. Regulating morphologies and near-infrared photothermal conversion of perylene bisimide via sequence-dependent peptide self-assembly. Chem. Commun. 2018, 54, 2208-2211. [CrossRef]

30. Moghaddam, R.S.; Draper, E.R.; Wilson, C.; Heidari, H.; Adams, D.J. Effect of electric field on the electrical properties of a self-assembled perylene bisimide. Rsc Adv. 2018, 8, 34121-34125. [CrossRef]

31. Nandi, M.; Maiti, B.; Banerjee, S.; De, P. Hydrogen bonding driven self-assembly of side-chain amino acid and fatty acid appended poly (methacrylate) s: Gelation and application in oil spill recovery. J. Polym. Sci. Part. A Polym. Chem. 2019, 57, 511-521. [CrossRef]

32. Sukul, P.K.; Singh, P.K.; Maji, S.K.; Malik, S. Aggregation induced chirality in a self assembled perylene based hydrogel: Application of the intracellular pH measurement. J. Mater. Chem. B 2013, 1, 153-156. [CrossRef]

33. Han, D.; Han, J.; Huo, S.; Qu, Z.; Jiao, T.; Liu, M.; Duan, P. Proton triggered circularly polarized luminescence in orthogonal-and co-assemblies of chiral gelators with achiral perylene bisimide. Chem. Commun. 2018, 54, 5630-5633. [CrossRef] [PubMed]

34. Li, Y.; Wang, N.; Gan, H.; Liu, H.; Li, H.; Li, Y.; He, X.; Huang, C.; Cui, S.; Wang, S. Synthesis and characterization of 3, 5-bis (2-hydroxyphenyl)-1, 2, 4-triazole functionalized tetraaryloxy perylene bisimide and metal-directed self-assembly. J. Org. Chem. 2005, 70, 9686-9692. [CrossRef] [PubMed]

35. Li, S.; Long, T.; Wang, Y.; Yang, X. Self-assembly, protonation-dependent morphology, and photophysical properties of perylene bisimide with tertiary amine groups. Dye. Pigment. 2020, 173, 107896. [CrossRef]

36. Zang, L.; Che, Y.; Moore, J.S. One-dimensional self-assembly of planar $\pi$-conjugated molecules: Adaptable building blocks for organic nanodevices. Acc. Chem. Res. 2008, 41, 1596-1608. [CrossRef]

37. Li, A.D.; Wang, W.; Wang, L.Q. Folding versus self-assembling. Chem. A Eur. J. 2003, 9, 4594-4601. [CrossRef]

38. Zhong, L.; Xing, F.; Shi, W.; Yan, L.; Xie, L.; Zhu, S. Synthesis, spectra, and electron-transfer reaction of aspartic acid-functionalized water-soluble perylene bisimide in aqueous solution. ACS Appl. Mater. Interfaces 2013, 5, 3401-3407. [CrossRef]

39. Xu, Z.; He, B.; Wei, W.; Liu, K.; Yin, M.; Yang, W.; Shen, J. Highly water-soluble perylenediimide-cored poly (amido amine) vector for efficient gene transfection. J. Mater. Chem. B 2014, 2, 3079-3086. [CrossRef]

40. Yang, L.; Shi, M.; Wang, M.; Chen, H. Synthesis, electrochemical, and spectroscopic properties of soluble perylene monoimide diesters. Tetrahedron 2008, 64, 5404-5409. [CrossRef]

41. Xu, L.Q.; Wang, L.; Zhang, B.; Lim, C.H.; Chen, Y.; Neoh, K.-G.; Kang, E.-T.; Fu, G.D. Functionalization of reduced graphene oxide nanosheets via stacking interactions with the fluorescent and water-soluble perylene bisimide-containing polymers. Polymer 2011, 52, 2376-2383. [CrossRef]

42. Georgiev, N.I.; Said, A.I.; Toshkova, R.A.; Tzoneva, R.D.; Bojinov, V.B. A novel water-soluble perylenetetracarboxylic diimide as a fluorescent $\mathrm{pH}$ probe: Chemosensing, biocompatibility and cell imaging. Dye. Pigment. 2019, 160, 28-36. [CrossRef]

43. Kazmaier, P.M.; Hoffmann, R. A theoretical study of crystallochromy. Quantum interference effects in the spectra of perylene pigments. J. Am. Chem. Soc. 1994, 116, 9684-9691. [CrossRef]

44. Adachi, M.; Murata, Y.; Nakamura, S. Spectral similarity and difference of naphthalenetetracarboxylic dianhydride, perylenetetracarboxylic dianhydride, and their derivatives. J. Phys. Chem. 1995, 99, 14240-14246. [CrossRef]

45. Görl, D.; Soberats, B.; Herbst, S.; Stepanenko, V.; Würthner, F. Perylene bisimide hydrogels and lyotropic liquid crystals with temperature-responsive color change. Chem. Sci. 2016, 7, 6786-6790. [CrossRef] [PubMed]

46. Sun, P.; Wu, Q.; Sun, X.; Miao, H.; Deng, W.; Zhang, W.; Fan, Q.; Huang, W. J-Aggregate squaraine nanoparticles with bright NIR-II fluorescence for imaging guided photothermal therapy. Chem. Commun. 2018, 54, 13395-13398. [CrossRef]

47. Zhu, M.; Chen, Y.; Zhang, X.; Chen, M.; Guo, H.; Yang, F. Perylene bisimide with diphenylacrylonitrile on side-chain: Strongly fluorescent liquid crystal with large pseudo stokes shift based on AIE and FRET effect. Soft Matter 2018, 14, 6737-6744. [CrossRef]

48. Che, Y.; Yang, X.; Liu, G.; Yu, C.; Ji, H.; Zuo, J.; Zhao, J.; Zang, L. Ultrathin n-type organic nanoribbons with high photoconductivity and application in optoelectronic vapor sensing of explosives. J. Am. Chem. Soc. 2010, 132, 5743-5750. [CrossRef] 
49. Guo, Z.; Wang, K.; Yu, P.; Wang, X.; Lan, S.; Sun, K.; Yi, Y.; Li, Z. Impact of linear alkyl length on the assembly of twisted perylene bisimides: From molecular arrangement to nanostructures. Chem. An. Asian J. 2017, 12, 2827-2833. [CrossRef] [PubMed]

50. Che, Y.; Datar, A.; Balakrishnan, K.; Zang, L. Ultralong nanobelts self-assembled from an asymmetric perylene tetracarboxylic diimide. J. Am. Chem. Soc. 2007, 129, 7234-7235. [CrossRef]

(C) 2020 by the authors. Licensee MDPI, Basel, Switzerland. This article is an open access article distributed under the terms and conditions of the Creative Commons Attribution (CC BY) license (http://creativecommons.org/licenses/by/4.0/). 